\title{
Perceived health and its relation with macrosocial and individual factors in children from two departments of Tucumán, Argentina
}

\author{
María L. Cordero, Specialist B.S., ${ }^{a}$ Verónica Mamondi, Master of Science, ${ }^{b}$ \\ Silvina Berra, M.D. and Professor ${ }^{b}$ and María F. Cesani, M.D.
}

a. Social Studies Institute (Instituto Superior de Estudios Sociales, ISES). Universidad Nacional de Tucumán (UNT). National Scientific and Technical Research Council (CONICET). Technological and Scientific Center (Centro Científico Tecnológico, CCT), Tucumán. San Miguel de Tucumán. Tucumán. Argentina.

b. Center for Epidemiological Research and Health Services, Public Health School, Universidad Nacional de Córdoba. Ciudad Universitaria. Córdoba.

c. Veterinarian Genetics Institute (Instituto de Genética Veterinaria, IGEVET).

Universidad

Nacional de La Plata. CONICET CCT. La

Plata. Buenos Aires.

E-mail adress:

María L. Cordero, Specialist B.S. lcordero@ises.org.ar

Financiamiento: The main author was granted a doctoral fellowship by the National Scientific and Technical Research Council (Consejo Nacional de Investigaciones Científicas y Técnicas, CONICET).

Conflict of interest: None.

Received: 9-13-2016 Accepted: 1-23-2017

\begin{abstract}
Introduction: The assessment of health-related quality of life (HRQoL) during childhood favors the identification of factors that affect growth and development. The objectives of this study were: a) to describe the HRQoL in children between 8.0 and 11.9 years old living in the Province of Tucumán; and b) to assess whether the HRQoL varies in relation to macrosocial (quality of life in the department, urban/rural household, socioeconomic status) and individual (age and sex) factors.

Population and methods: Quantitative and cross-sectional study among students from the departments of Yerba Buena and Simoca. The KIDSCREEN-52 questionnaire was administered to measure the HRQoLdimensions, and Student's $t$ tests, analysis of variance and multivariate logistic regression analysis to evaluate the data according to macrosocial and individual factors. Results: A total of 1647 surveys were analyzed. Younger students and of male sex, in general, had a better perception of their health. Yerba Buena residents had mean scores that were significantly lower in the financial resources dimension, as compared to residents of Simoca (45.3 vs. 46.7, $p: 0.01)$. There was no association between the socioeconomic status and the HRQoL. Children from rural areas had the lowest scores in most dimensions, with significant differences in selfperception (51.3 vs. 53.0, $p: 0.01$ ) and $\operatorname{mood}(43.2$ vs. $44.5, p: 0.03$ )

Conclusions: Perceived health of children from Yerba Buena and Simoca varied in relation to macrosocial and individual factors. In Yerba Buena, the perception of financial resources was worse than in Simoca. In general, the opinion of children from urban areas was more favorable than that of children from rural areas. Younger students and of male sex had a better perception of their health status.
\end{abstract}

Key words: quality of life, children, urban area, rural area, health.

http:/ / dx.doi.org/10.5546/aap.2017.eng.415

To cite: Cordero ML, Mamondi V, Berra S, et al. Perceived health and its relation with macrosocial and individual factors in children from two departments of Tucumán, Argentina. Arch Argent Pediatr 2017;115(4):415-423.

\section{INTRODUCTION}

The investigation on the quality of life dates back to 1950-1960. Initially, it was linked to the study of objective and material indicators of living conditions and environmental factors. Argentina has some background in this field, such as the quality of life index (QoLI), developed by Velázquez, based on census data and other statistical sources. ${ }^{1}$ This index analyzes and arranges in order of importance socioeconomic (education, health and housing) and physical/ environmental (flood risk, seismic and volcanic activity risk, among others) factors in each department. Its analysis shows that, historically, the worst wellbeing conditions have been in the Great North region. ${ }^{1,2}$

In the 80 s, research about quality of life started considering subjective factors. ${ }^{3}$ Thus, the WHO defines Quality of Life as individuals' perception of their position in life in the context of the culture and value systems in which they live and in relation to their goals, expectations, standards and concerns. ${ }^{4}$ As a result, studies about perceived health or health-related quality of life begin to emerge, understanding HRQoL as a multidimensional construct within the wider concept of quality of life. HRQoL evaluates, from the perspective of each individual or their proxies, specific aspects that have an impact on health, both internal (physical and mental), and external. ${ }^{5}$ In this sense, analyzing the approach to health perceived during childhood favors the identification of factors that affect growth and development, as well as the implementation of early interventions on those contributing to their vulnerability. ${ }^{6}$ 
In Argentina, studies on childhood HRQoL are recent and are mainly related to contexts of disease. There are scarce studies on healthy population..$^{7-9}$ Among the latter ones, there are records in students from Córdoba and Bahía Blanca which have identified differences in perceived health in different social and environmental conditions. ${ }^{9,10}$ These studies suggest that younger children and of male sex tend to have a more favorable HRQoL. However, in many provinces of Argentina there is no information related to these aspects.

In Tucumán, records are scarce and limited to adolescents from the capital city of the province. ${ }^{11}$ It is not known whether there are differences in relation to socioenvironmental features, such as residence, sex and age.

The objectives of this study were: a) to describe the HRQoL of children between 8.0 and 11.9 years old living in the Province of Tucumán; and b) to assess whether the perceived health varied in relation to macrosocial (QoLI in the department, urban/rural household, socioeconomic level [SEL]) and individual (age and sex) factors. The working hypothesis proposed was that perceived health during childhood varies according to the context of residence, family socioeconomic status, age and sex.

\section{POPULATION AND METHODS}

\section{Study setting}

Tucumán is one of the nine provinces that are part of the Argentine Great North region. Although it is the smallest province $\left(22,524 \mathrm{~km}^{2}\right)$, it is also one of the most densely populated $\left(72.04 \mathrm{inh} / \mathrm{km}^{2}\right)$. Its economy is characterized by the exploitation of natural resources (particularly, lemon and sugar agricultural and industrial complexes), tertiary and service activities. ${ }^{12}$

It has a huge internal heterogeneity, as a result of deep-rooted and persistent social, economic and environmental inequalities. One of the 17 departments of the province, Yerba Buena (YB) --with a population of 73,574 inhabitantsis considered one of the best places to live in Argentina (its QoLI is at the top of the province ranking and of the Argentine Great North), while Simoca (SIM) -with a population of $30,000-$ mainly rural, bears the worst conditions (its QoLI is below the 25 percentile, both at a provincial and at a national level). ${ }^{2}$

\section{Design and population}

A quantitative and cross-sectional study was conducted in public elementary schools in the departments of YB and SIM during the 2014-2015 School Year.

Once the Directorate of Elementary Schools granted the corresponding authorization, ten schools from YB and eight from SIM were selected by convenience. The eligible population included all students from 8 to 11.9 years of age. Children with chronic or acute conditions, under drug treatment at the time of the study were excluded, as well as those who did not have a written authorization from their parents / guardians, and those who refused to take part in the study, even if they had their parents' / guardians' authorization.

The number of enrolled students, both in public and private schools, in both departments was 7192 (YB: 3890; SIM: 3302). ${ }^{13}$ To estimate the necessary, minimum sample size, it was considered that HRQoL scale average values had a standard deviation (SD) of 10 points, and accuracy was established in $+/$ - 2 points. It was estimated that it would be necessary to include 95 randomly selected subjects to achieve a population average with a $95 \%$ confidence interval, and 295 subjects per group or 885 subjects in the total sample size to detect intergroup differences with an alpha risk of 0.05 and a beta risk of 0.2 (two-tailed contrast).

\section{Outcome measures considered and their collection}

Quality of Life in the department: According to QoLI values, ${ }^{2}$ the YB and SIM departments were considered as having a high and low QoLI, respectively.

Place of residence: Following the guidelines of the National Statistics and Censuses Institute of Argentina (Instituto Nacional de Estadísticas y Censos, INDEC), ${ }^{14}$ areas with more or fewer than 2000 inhabitants were considered urban or rural; respectively.

SEL: Determined based on the percentage of households with unmet basic needs (UBN) in each census tract. The UBNs referred to material manifestations which showed a lack of access to goods and services, such as housing, drinking water and health care, among others. ${ }^{14}$ In relation to the extension of UBNs in the province, three equivalent ranges were calculated, thus differentiating households into low SEL, medium SEL and high SEL.

HRQoL: The version for children of the KIDSCREEN-52 questionnaire -adapted and validated for the Argentinean population-- 
was conducted. This questionnaire provides information on 10 dimensions through 52 items (Table 1). ${ }^{15,16}$ The answers to the items were categorized on a five-option Likert scale evaluating the frequency or intensity of the attribute with a recall period of a week. To minimize distractions, the questionnaire was completed in a dedicated room, prepared for small group work. The administration of the questionnaire was guided by one of the authors (MLC).

Sex and age: This information was obtained from the National Identity Document of each child.

\section{Statistical analysis}

The analysis of census microdata was done with the REDATAM software and databases of the National Population, Households and Housing Census of 2010. ${ }^{14}$

Rasch scores were calculated for each HRQoL dimension, and they were later transformed into values with a mean of 50 and a SD of 10 . Scores $>60$ indicated a better HRQoL and values $<40$, a compromised HRQoL. ${ }^{17}$

Student's t tests were used to identify the statistical association between HRQoL, QoLI, place of residence and sex, and the analysis of variance (ANOVA) for HRQoL, SEL and age, considering a significance level of $p<0.05$. Likewise, the effect size (ES) was calculated to determine the magnitude of differences: values ranging from 0.20 to 0.50 indicated small effects; from 0.51 to 0.80 , moderate effects; and $>0.80$, large effects. ${ }^{18}$

Lastly, odds ratios (OR) were estimated for the association between QoLI and place of residence, with the presence of low HRQoL scores ( $<1 \mathrm{SD}$ ). The association was assessed using a Wald test. In those HRQoL dimensions with a $p$ value $\leq 0.10$, a multivariate logistic regression model was adjusted to analyze the effect of contextual variables, regardless of the age, sex and SEL. Adjusted ORs were estimated, as well as their confidence intervals at a 95\% level $(95 \%$ CI). A complete statistical analysis was performed using the SPSS 19.0 software.

\section{Ethical considerations}

Participation of children required the written consent of their parents or guardians, as well as their own assent. The research was carried out following national and international guidelines on human research. The study protocol was approved by the Ethics and Research Committee under the Department of Epidemiology of the Healthcare System of the Province of Tucuman.

TABLE 1. Dimensions and examples of statements in the KIDSCREEN-52 ${ }^{17}$ questionnaire

\begin{tabular}{|c|c|c|}
\hline Dimension & Definition & Question example \\
\hline $\begin{array}{l}\text { Physical well-being } \\
\text { (Ph. well-being) }\end{array}$ & $\begin{array}{l}\text { Questions on the ability to move, play or } \\
\text { do strenuous physical activity. }\end{array}$ & Did your feel well and physically fit? \\
\hline $\begin{array}{l}\text { Psychological well-being } \\
\text { (Psy. well-being) }\end{array}$ & $\begin{array}{l}\text { How frequently do you experience positive } \\
\text { feelings? }\end{array}$ & Did you have a good time? \\
\hline $\begin{array}{l}\text { Moods and emotions } \\
\text { (MOOD) }\end{array}$ & $\begin{array}{l}\text { Questions about negative experiences, } \\
\text { depression and stress. }\end{array}$ & $\begin{array}{l}\text { Did you have the feeling that } \\
\text { everything in your life was wrong? }\end{array}$ \\
\hline $\begin{array}{l}\text { Self-perception } \\
\text { (Self-p.) }\end{array}$ & $\begin{array}{l}\text { It includes self-perception, satisfaction with } \\
\text { one's physical appearance. }\end{array}$ & $\begin{array}{l}\text { Have you been worried about your } \\
\text { appearance? }\end{array}$ \\
\hline $\begin{array}{l}\text { Autonomy } \\
\text { (Autonom.) }\end{array}$ & $\begin{array}{l}\text { It includes freedom of choice, } \\
\text { self-sufficiency and independence. }\end{array}$ & Did you have enough time for yourself? \\
\hline $\begin{array}{l}\text { Relation with parents } \\
\text { and family life } \\
\text { (Family life) }\end{array}$ & $\begin{array}{l}\text { It examines the quality of interactions } \\
\text { and feelings towards their caregivers. }\end{array}$ & Did you feel loved by your parents? \\
\hline $\begin{array}{l}\text { Relation with friends } \\
\text { and social support } \\
\text { (Friends) }\end{array}$ & $\begin{array}{l}\text { It involves the degree to which responders } \\
\text { feel accepted and their ability to make } \\
\text { and keep friends. }\end{array}$ & $\begin{array}{l}\text { Did you and your friends } \\
\text { help each other? }\end{array}$ \\
\hline $\begin{array}{l}\text { School environment } \\
\text { (School) }\end{array}$ & $\begin{array}{l}\text { Questions about their perception of their own } \\
\text { cognitive capacity, learning and feelings } \\
\text { about the school. }\end{array}$ & Did you feel happy at school? \\
\hline $\begin{array}{l}\text { Social acceptance } \\
\text { (Social acc.) }\end{array}$ & Feelings of rejection or bullying. & $\begin{array}{l}\text { Did other children threaten or } \\
\text { intimidate you? }\end{array}$ \\
\hline $\begin{array}{l}\text { Financial resources } \\
\text { (Fin. Resources) }\end{array}$ & $\begin{array}{l}\text { Questions on the perception of the family's } \\
\text { financial resources. }\end{array}$ & $\begin{array}{l}\text { Did you have enough money to do } \\
\text { the same activities as your friends? }\end{array}$ \\
\hline
\end{tabular}




\section{RESULTS}

Of the population listed in institutional records (2338 students), 543 were not authorized by their parents/guardians, refused to take part or were absent on the day of sampling. A total of 1647 surveys were included in the analysis. Incomplete protocols -with at least one unanswered question (39)-, protocols answered by children whose ages were outside the scope of the study (25) and those living in mixed census tracts, or in other departments (84) were excluded from the analysis. Table 2 shows the sample composition.

The means and SD of each dimension in the HRQoL survey indicated that the school environment and the psychological well-being were awarded the highest scores, while mood and social acceptance were the lowest. However, most dimensions were within normal values $(\mathrm{SD} \pm 1)$ (Table 3).

Figures 1 and 2 show mean scores, and results of Student's $t$ tests and ANOVA for each dimension.

In relation to age, significant differences were found between 8 and 11.9 years of age. Older students had lower scores, compared to younger students, in: physical well-being ( $p: 0.01$; ES: $0.27)$, psychological well-being ( $p$ : 0.01; ES: 0.29), friendship and social support ( $p$ : 0.03; ES: 0.20) and school environment ( $p$ : 0.01; ES: 0.43). In all cases, the ES was small (Figure 1. A).

Although boys had higher scores in most dimensions, significant and minor differences were only observed in social support ( $p: 0.02$; ES: 0.11$)$. The school environment dimension ( $p$ :
0.01; ES: 0.28) was the only one in which girls had significantly higher scores (Figure 1. B).

YB children had significantly lower scores in the financial resources dimension ( $p: 0.01)$, when compared to SIM children (Figure 2. A).

With respect to place of residence, rural children had lower scores in most dimensions. Significant differences were observed in selfperception ( $p$ : 0.01) and mood (p: 0.03) (Figure 2. B).

In relation to SEL, no significant differences were observed in any dimension (Figure 2. C).

Lastly, the multivariate analysis showed that low social acceptance and a bad mood were more frequent in $\mathrm{YB}$, compared to SIM, and that living in a rural area increased the likelihood of experiencing low self-perception and a worse mood (Table 4).

TABLE 3. Mean values and standard deviations for each dimension in the health-related quality of life survey

\begin{tabular}{lcc}
\hline HRQoL dimensions & M & SD \\
\hline Physical well-being & 50.0 & 10.0 \\
Psychological well-being & 55.2 & 9.1 \\
Moods and emotions & 44.1 & 10.4 \\
Self-perception & 52.5 & 10.5 \\
Autonomy & 51.6 & 10.0 \\
Parent relations and family life & 52.0 & 9.9 \\
Friendships and social support & 52.7 & 10.7 \\
School environment & 59.2 & 10.6 \\
Social acceptance & 42.4 & 12.6 \\
Financial resources & 45.9 & 9.4 \\
\hline
\end{tabular}

M: mean; SD: standard deviation;

HRQoL: health-related quality of life.

TABLE 2. Sample characteristics $(N=1647)$

\begin{tabular}{|c|c|c|c|}
\hline & Total $(n=1647)$ & Yerba Buena $(n=985)$ & Simoca $(n=662)$ \\
\hline \multicolumn{4}{|l|}{ Age } \\
\hline 8 years old & $23.6 \%(\mathrm{n}=388)$ & $21.8 \%(\mathrm{n}=215)$ & $26.1 \%(n=173)$ \\
\hline 9 years old & $21.5 \%(\mathrm{n}=354)$ & $22.0 \%(n=217)$ & $20.7 \%(\mathrm{n}=137)$ \\
\hline 10 years old & $27.9 \%(n=460)$ & $27.6 \%(\mathrm{n}=272)$ & $28.4 \%(\mathrm{n}=188)$ \\
\hline 11 years old & $27.0 \%(\mathrm{n}=445)$ & $28.5 \%(\mathrm{n}=281)$ & $24.8 \%(\mathrm{n}=164)$ \\
\hline \multicolumn{4}{|l|}{ Sex } \\
\hline Male & $52.0 \%(\mathrm{n}=856)$ & $51.8 \%(\mathrm{n}=510)$ & $52.3 \%(n=346)$ \\
\hline Female & $48.0 \%(\mathrm{n}=791)$ & $48.2 \%(\mathrm{n}=475)$ & $47.7 \%(n=316)$ \\
\hline \multicolumn{4}{|c|}{ Place of residence } \\
\hline Urban & $70.2 \%(\mathrm{n}=1157)$ & $93.6 \%(\mathrm{n}=922)$ & $35.5 \%(\mathrm{n}=235)$ \\
\hline Rural & $29.8 \%(n=490)$ & $6.4 \%(\mathrm{n}=63)$ & $64.5 \%(n=427)$ \\
\hline \multicolumn{4}{|c|}{ Socioeconomic level } \\
\hline High & $29.5 \%(\mathrm{n}=486)$ & $31.7 \%(\mathrm{n}=312)$ & $26.3 \%(\mathrm{n}=174)$ \\
\hline Middle & $40.6 \%(\mathrm{n}=669)$ & $31.9 \%(n=314)$ & $53.6 \%(\mathrm{n}=355)$ \\
\hline Low & $29.9 \%(n=492)$ & $36.4 \%(\mathrm{n}=359)$ & $20.1 \%(\mathrm{n}=133)$ \\
\hline
\end{tabular}




\section{DISCUSSION}

Considering that childhood is an ontogenetic stage, characterized by a high vulnerability to physical and psychosocial risks, but that it also responds positively to protecting factors, ${ }^{19}$ this study is relevant because it is the first one to assess the HRQoL of healthy children in Tucumán. Most participants had positive feedback in relation to their school environment, emotions and satisfaction with their lives. However, mood, social acceptance and the perception of their families' financial situation were, in general, negative.
It was noted that, as children grew older, their self-perception of health was worse. This was particularly evident in 11-year-olds, who had a negative input in relation to the physical, psychological, social support, and -in particularschool environment dimensions. Similar results have been reported in other studies, where the HRQoL components are less favorable at older ages. ${ }^{20,21}$ This may be linked to biological, psychological and physical changes inherent to said age, during which self-perception becomes more complex, which may result in worse health perceptions. ${ }^{22}$

FiguRE 1. Health-related quality of life dimensions per age (A) and sex (B): means and confidence intervals (95\%) $(N=1647)$. Student's t tests and analysis of variance

A.

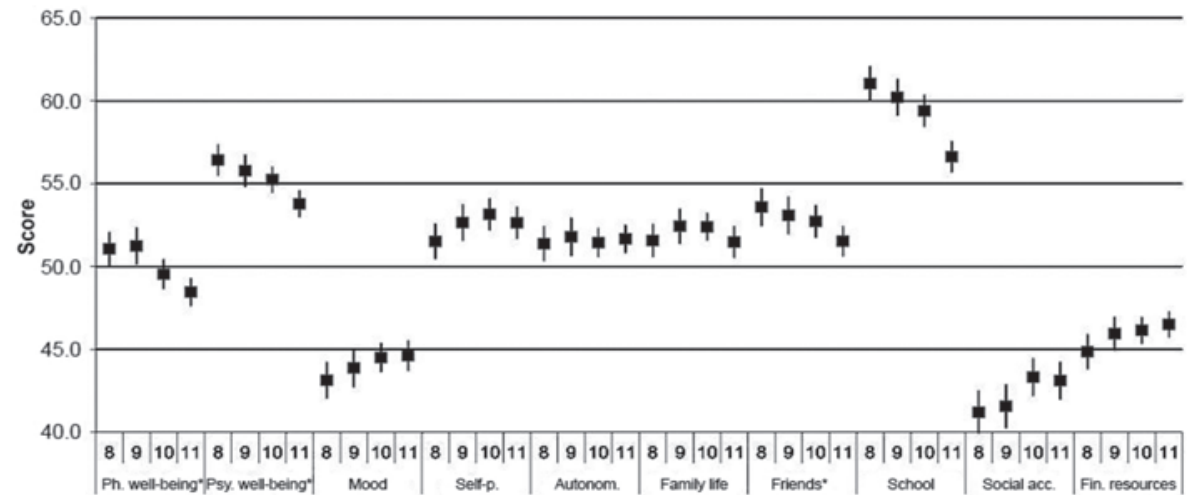

B.

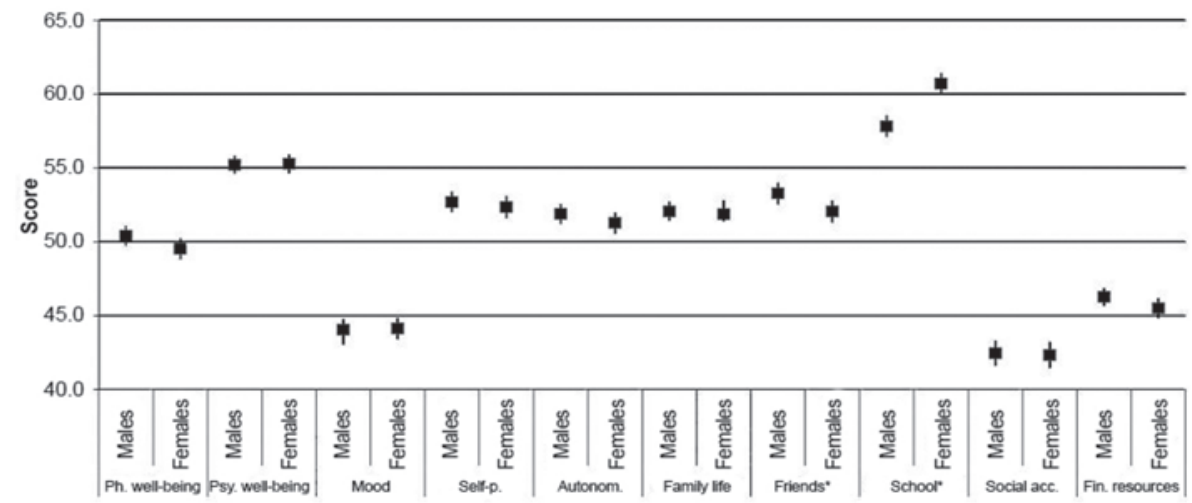

Significant differences $(p>0.05)$

Ph. well-being: Physical well-being; Psy. well-being: Psychological well-being; Mood: Moods and emotions; Self-p.: Self-perception; Autonom.: Autonomy; Family life: Parental relation and family life; Friends: Friendships and social support; School: School environment; Social acc.: Social acceptance; Fin. resources: Financial resources. 
FIGURE 2. Health-related quality of life dimensions according to the quality of life in each district (A), place of residence (B) and the socioeconomic level $(C)$ : means and confidence intervals $(95 \%)(N=1647)$. Student's tests and analysis of variance

A.

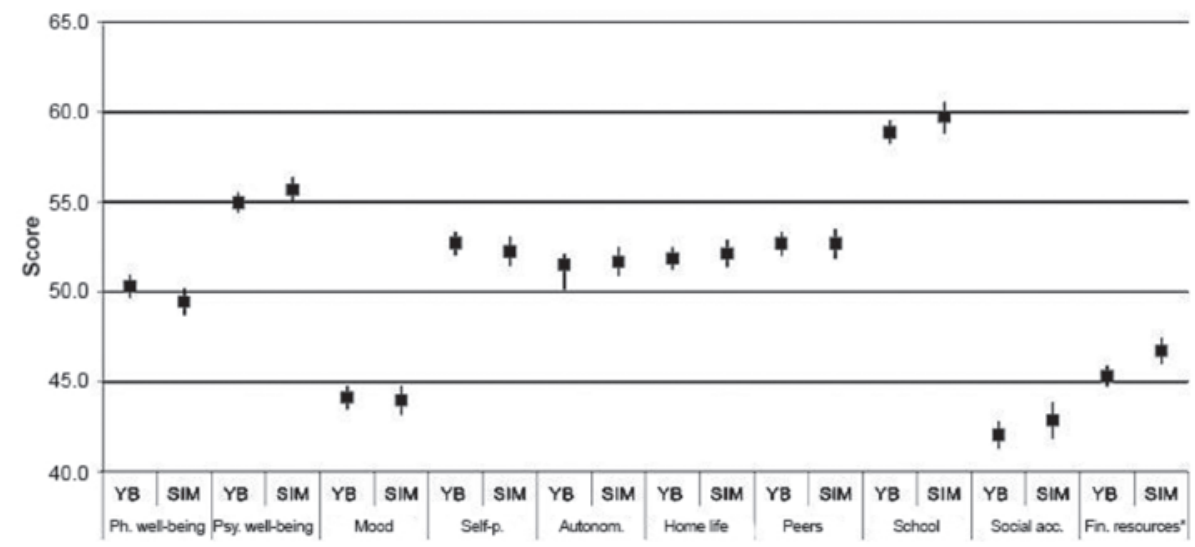

B.

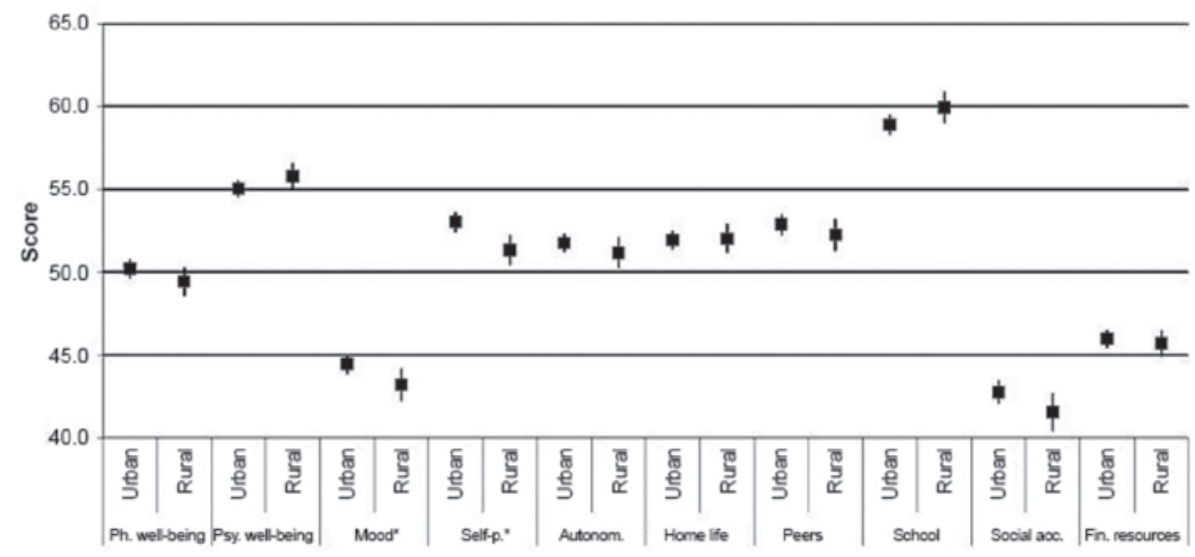

c.

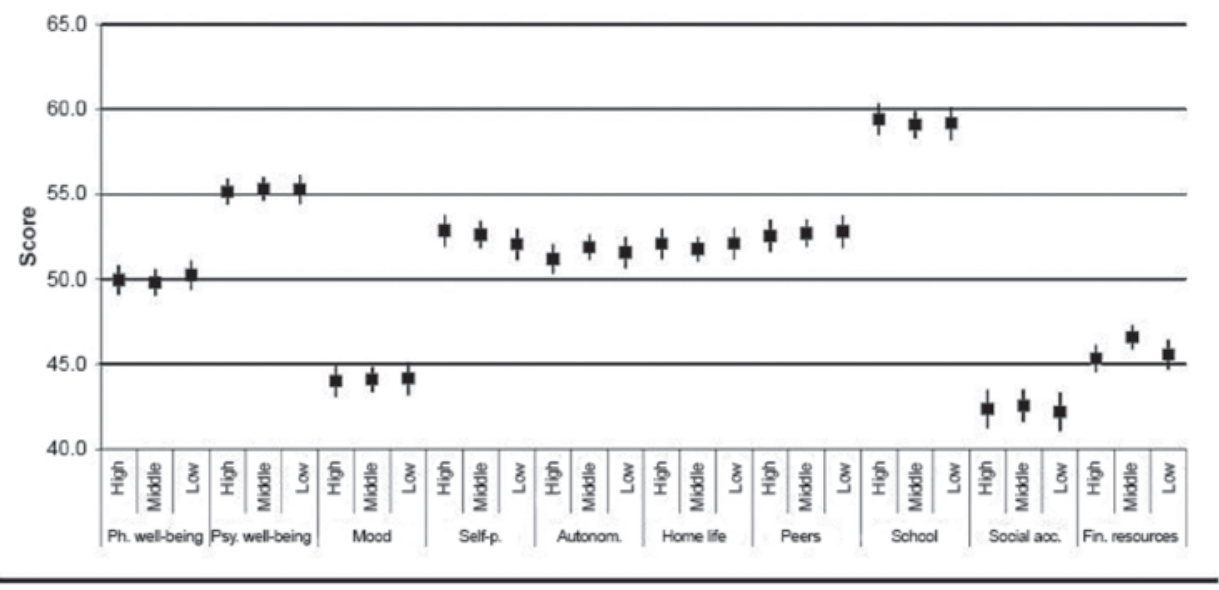

* Significant differences $(\mathrm{p}>0,05)$.

YB: Yerba Buena; SIM: Simoca.

Ph. well-being: Physical well-being; Psy. well-being: Psychological well-being; Mood: Moods and emotions; Self-p.: Self-perception; Autonom.: Autonomy; Family life: Parental relation and family life; Friends: Friendships and social support;

School: School environment; Social acc.: Social acceptance; Fin. resources: Financial resources. 
In agreement with the data reported for other populations, girls showed a lower HRQoL. ${ }^{21,23-25}$ However, their perceptions of the school environment were better. In this sense, it has been proposed that girls usually get better grades and are less likely to repeat the year, which is very important in the perception children have of their school environment. ${ }^{22,24,25}$ Boys had better scores in the Friends dimension, which could be related to male socialization processes through playing (horseplay and sports), activities that foster interpersonal relations. ${ }^{22}$ Sex differences may be attributed to social expectations of male and female roles in the family and society at large, which promote different attitudes and behaviors from childhood. 22,24

It was surprising that YB schoolchildren-the department with the best QoLI- had a worse appreciation of their families' financial resources than SIM children. This apparent paradox may be related to the social and regional fragmentation that characterizes YB. YB is considered to be "two cities in one," where families with opposing economic conditions, lifestyle and social standing coexist. ${ }^{26,27}$ In some societies, where inequality is so marked, patterns and concepts of well-being are stratified, and the idea of quality of life is related to the well-being of upper strata. ${ }^{28}$ In YB, constant exposure of children from lower income social levels to realities so different from their own might account for the negative perception they have of their own context. Nevertheless, it is worth noting that no significant differences were found when the HRQoL was analyzed in relation to SEL.

Feelings of depression during childhood have not been thoroughly studied, perhaps due to their low prevalence versus other stages in life. However, when they occur, they may affect the process of development, since they are linked to complex interactions among the cognitive, socio-emotional, biologic and representational systems. ${ }^{29-31}$ García and Siverio ${ }^{29}$ suggest that children's moods may be negatively impacted by the loss of loved ones, divorce, family issues, rejection from their peers, loneliness and violence, among others. In the rural areas studied, where

TABLE 4. Health-related quality of life per department and place of residence: crude and adjusted odds ratios

\begin{tabular}{|c|c|c|c|c|}
\hline & Number of children $(\%)$ & $\begin{array}{l}\text { Bivariate analysis } \\
\text { COR }(95 \% \mathrm{CI})\end{array}$ & $p$ & $\begin{array}{c}\text { Multivariate analysis } \\
\text { aOR }(95 \% \text { CI) }\end{array}$ \\
\hline \multicolumn{5}{|l|}{ Low mood } \\
\hline \multicolumn{5}{|c|}{ Variables and categories } \\
\hline \multicolumn{5}{|c|}{ District } \\
\hline Yerba Buena & $346(35.1 \%)$ & * & & \\
\hline Simoca & $217(32.8 \%)$ & $0.90(0.73-1.12)$ & 0.33 & $0.68(0.51-0.90)^{* *}$ \\
\hline \multicolumn{5}{|l|}{ Place of residence } \\
\hline Urban & $378(32.7 \%)$ & * & & \\
\hline Rural & $185(37.8 \%)$ & $1.25(1.01-1.56)$ & $0.05^{+}$ & $1.62(1.21-2.19)^{* *}$ \\
\hline \multicolumn{5}{|l|}{ Low self-perception } \\
\hline \multicolumn{5}{|c|}{ Variables and categories } \\
\hline \multicolumn{5}{|c|}{ District } \\
\hline Yerba Buena & $78(7.9 \%)$ & * & & \\
\hline Simoca & $57(8.6 \%)$ & $1.09(0.77-1.57)$ & 0.62 & $0.75(0.45-1.23)$ \\
\hline \multicolumn{5}{|l|}{ Place of residence } \\
\hline Urban & $84(7.3 \%)$ & * & & \\
\hline Rural & $51(10.4 \%)$ & $1.48(1.03-2.14)$ & $0.03^{+}$ & $1.81(1.09-2.99)^{* *}$ \\
\hline \multicolumn{5}{|l|}{ Low social acceptance } \\
\hline \multicolumn{5}{|c|}{ Variables and categories } \\
\hline \multicolumn{5}{|l|}{ District } \\
\hline Yerba Buena & $492(49.9 \%)$ & * & & \\
\hline Simoca & $304(45.9 \%)$ & $0.85(0.69-1.04)$ & 0.10 & $0.72(0.55-0.94)^{* *}$ \\
\hline \multicolumn{5}{|l|}{ Place of residence } \\
\hline Urban & $554(47.9 \%)$ & * & & \\
\hline Rural & $242(49.4 \%)$ & $1.06(0.86-1.31)$ & 0.58 & $1.31(0.99-1.73)$ \\
\hline
\end{tabular}

cOR: Crude odds ratio obtained by bivariate logistic regression.

aOR: Adjusted odds ratio obtained by multivariate logistic regression.

* Category of reference.

** Statistically significant differences $(\mathrm{p}<0.05)$.

$+\mathrm{p} \leq 0.10$, variables included in the multivariate analysis. 
adults are mainly involved in agricultural and industrial activities around the production of lemon and sugarcane, temporary and prolonged migration of parents in the periods between harvests is frequent. This situation may explain the urban and rural differences observed in relation to mood and self-perception. However, since depressive moods during childhood are multicausal, further research is needed to look into this dimension of the HRQoL in rural areas.

Results obtained support the value of combining subjective and objective quality of life indicators to better understand health issues, particularly, when assessing regions with marked contrasts in their living conditions. The fact that the sample did not include children from private schools may be a limitation of the study; however, it provides valuable information about a vulnerable population group. Lastly, the following strengths can be mentioned: 1) It provides information about the HRQoL among children in the province of Tucumán; 2 ) it is the first study to assess potential differences in the perception of health of children living in urban and rural areas in Argentina; and 3) it provides new insights that may be used to plan public policies aimed at improving children's living conditions.

\section{CONCLUSION}

The perceived health of children from Tucumán living in Yerba Buena and Simoca varied in relation to macrosocial and individual aspects. In Yerba Buena, the perception of financial resources was worse than that in Simoca. In general, the opinion of children from urban areas was more positive than that of children from rural areas. Lastly, younger students and of male sex had a better perception of their health status.

\section{Acknowledgments}

The authors would like to thank the supervisors, principals, teachers, and students of the participating schools. The authors would also like to thank Fernando Longhi for his critical reading and his contributions to the manuscript; and María Cristina Muñe for her thorough and detailed revision.

\section{REFERENCES}

1. Velázquez GA. Geografía, calidad de vida y fragmentación en la Argentina de los noventa. Análisis regional y departamental utilizando SIG's. Tandil: Universidad Nacional del Centro de la Provincia de Buenos Aires, CIGCentro de Investigaciones Geográficas; 2001.
2. VelázquezGA, Mikkelsen C, LinaresS, etal. Calidad de vida en Argentina. Ranking del bienestar por departamentos: 2010. Tandil: Universidad Nacional del Centro de la Provincia de Buenos Aires; 2014.

3. Arostegui Barandika I. Evaluación de la calidad de vida en personas adultas con retraso mental en la Comunidad Autónoma del País Vasco. Madrid:Universidad de Deusto; 1998.

4. World Health Organization. Programme on mental health. WHOQOL Measuring quality of life. Ginebra: WHO; 1997. [Accessed on: January 31, 2017]. Available at: http:/ / www. who.int/mental_health/media/68.pdf.

5. De Cunto C. ¿Qué es la calidad de vida relacionada con la salud? Conex Pediátr 2010;3:1-3.

6. Quiceno JM, Vinaccia Alpi S. Calidad de vida relacionada con la salud infantil: una aproximación conceptual. Psicol Salud 2008;18(1):37-44.

7. Roizen M, Figueroa C, Salvia L, et al. Calidad de vida relacionada con la salud en niños con enfermedades crónicas: comparación de la visión de los niños, sus padres y sus médicos. Arch Argent Pediatr 2007;105(4):305-13.

8. Pico $M$, Spirito $M$, Roizen $M$. Calidad de vida en niños y adolescentes con enfermedad celíaca: versión argentina del cuestionarioespecífico CDDUX. Acta Gastroenterol Latinoam 2012;42(1):12-9.

9. Mamondi V. Sobrepeso, obesidad y calidad de vida relacionada con la salud en niños y adolescentes escolarizados de la ciudad de Bahía Blanca. Córdoba: Universidad Nacional de Córdoba; 2011. [Accessed on: November17, 2016. Available at:http: / / lildbi.fcm.unc.edu. ar/lildbi/tesis/Mamondi_V_Maestria_Salud_Publica.pdf.

10. Rivera C, Mamondi V, Lavin Fueyo J, et al. Calidad de vida relacionada con la salud en niños con y sin trastornos crónicos: Estudio multicéntrico. Arch Argent Pediatr 2015;113(5):404-10.

11. Pinto GuedesD, Villagra AstudilloHA, Moya MoralesJM, et al. Calidad de vida relacionada con la salud de adolescentes latinoamericanos. Rev Panam Salud Pública 2014;35(1):46-52.

12. Osatinsky A. Economía, desocupación y pobreza en Catamarca y Tucumán (1980-2002). Rev Estud Reg Merc Trab 2007;3(6):157-78.

13. Ministerio de Educación Gobierno de Tucumán. Evolución de Matrícula según Departamento - Tucumán 1999-2016. Matricula educación modalidad común. [Accessed on: January 31, 2017]. Available at: http: / / www.educaciontuc. gov.ar/sistema/pdfs/ Informe2\%20-\%20Matricula\%20 por $\% 20$ departamento.pdf.

14. Instituto Nacional de Estadísticas y Censos. Censo Nacional de Población, Hogares y Viviendas 2010. Ciudad Autónoma de Buenos Aires, 2013. [Accessed on: January 31, 2017]. Available at: http: / / 200.51.91.245/argbin/RpWebEngine. exe $/$ PortalAction? \& MODE $=$ MAIN\&BASE $=C P V 2010 B \&$ MAIN=WebServerMain.inl.

15. Berra S, Bustingorry V, Henze C, et al. Adaptación transcultural del cuestionario KIDSCREEN para medir la calidad de vida relacionada con la salud en población argentina de 8 a 18 años. Arch Argent Pediatr 2009; 107(4): 307-14.

16. Berra S, Tebé C, Esandi M, et al. Fiabilidad y validez del cuestionario KIDSCREEN-52 para medir calidad de vida relacionada con la salud para población argentina de 8 a 18 años. Arch Argent Pediatr 2013;111(1):29-36.

17. The KIDSCREEN Group Europe. Los cuestionarios KIDSCREEN. Cuestionarios de calidad de vida para niños y adolescentes. Manual. Lengerich:PabstScience Publishers; 2006.

18. Cohen J. Statistical power analysis for the behavioral Sciences. 2nd ed. Hillsdale, NJ: Lawrence Earlbaum Associates;1988. 
19. Colomer-Revuelta C, Colomer-Revuelta J, Mercer R, et al. La salud en la infancia. Gac Sanit 2004;18(4):39-46.

20. Palacio-Vieira JA, Villalonga-Olives E, Valderas JM, et al. Changes in health-related quality of life (HRQoL) in a population-based sample of children and adolescents after 3 years of follow-up. Qual Life Res 2008;17(10):1207-15.

21. Aymerich M, Berra S, Guillamón I, et al. Desarrollo de la versión en español del KIDSCREEN: un cuestionario de calidad de vida para la población infantil y adolescente. Gac Sanit 2005;19(2):93-102.

22. Papalia D, Wendkos Olds S, Duskin Feldman R. Desarrollo Humano. 11.va ed. México: Mc Graw Hill; 2010.

23. Vélez Galárraga R, López Aguilà S, Rajmil L. Género y salud percibida en la infancia y la adolescencia en España. Gac Sanit 2009;23(5):433-9.

24. Vitale R, Degoy E, Berra S. Salud percibida y rendimiento académico en adolescentes de escuelas públicas dela ciudad de Córdoba. Arch Argent Pediatr 2015;113(6):526-33.

25. Halpern D, Benbow C, Geary D, et al. The Science of Sex
Differences in Science and Mathematics. Psychol Sci Public Interest 2007;8(1):1-51.

26. Malizia M, Paolasso P. Countries y barrios privados en Yerba Buena, Gran San Miguel de Tucumán, Argentina: nuevas formas de expansión urbana. Estud Demogr Urbanos 2009;24(3):583-613.

27. Castells M. La ciudad Informacional-Tecnología de la Información, reestructuración económica y el proceso urbano regional. Madrid: Alianza;1995.

28. Minayo MC, Hartz ZM, Buss PM. Qualidade de vida e saúde: um debate necessário. Ciênc Saúde Colet 2000;5(1):718.

29. García M, Siverio, M. La tristeza en niños, adolescentes y adultos: un análisis comparativo. Infanc Aprendiz 2005;28(4):453-69.

30. Villanueva Suárez C, García Sanz J. Especificidad del duelo en la infancia. Psiquiat Pública 2000;12(3):219-28.

31. Damon W,HartD. The development of self-understanding from infancy through adolescence. Child Development 1982;53(1):841-64. 